DOI: https://doi.org/10.36910/6775-2524-0560-2021-44-14

УДК 004.772

Анищенко Олексій Сергійович, аспірант, кафедра електроніки

https://orcid.org/0000-0002-8012-0920

Національний авіаційний університет

\title{
ЩОДО ПИТАННЯ ПЕРЕДАЧІ ТА ЗБЕРЕЖЕННЯ МАСИВІВ ГРАФІЧНИХ ДАНИХ У ГЛОБАЛЬНИХ І ЛОКАЛЬНИХ МЕРЕЖАХ
}

\begin{abstract}
Анищенко О. С. Щодо питання передачі та збереження масивів графічних даних у глобальних і локальних мережах. У статті розкрито питання передачі та збереження масивів графічних даних у глобальних і локальних мережах. Описано структуру сучасних комп'ютерних мереж, визначено основні проблеми, які виникають при передачі даних всередині мережі. Окреслено складність моделювання глобальних і локальних мереж. Зазначається, що побудова логічної системи управління передачею графічних даних у мережах дозволить підвищити швидкість передачі та знизити можливості втрати інформації. Описано вплив моделі Гілберта на лінію передачі даних та відокремлено механізм впливу прихованого харківського процесу на передачу даних. Деталізовано метод ідентифікації характеристик лінії передачі та вибору оптимального методу кодування сигналу, узгодженого 3 поточною частотною характеристикою лінії передачі. Розкрито стохастичну теорію управління в системах із прихованими марківськими процесами та обгрунтовано іiі вплив на задачі управління системами передачі даних. Підкреслено, що основною проблемою в організації локальних та глобальних мереж $є$ розподіл потоків даних за найкоротшими шляхами. До такої проблеми належать способи передачі даних, які вимагають мінімального часу, або шляхи 3 мінімальними перешкодами. Таким чином, на основі цього визначення, наголошено, що оптимізація шляху має здійснюватися за будь-якими технічними та економічними критеріями, а обрані шляхи мають гарантувати ефективне використання ліній та вершин зв'язку. Детально описано алгоритм Дейкстри та визначено напрямки його реалізації та впливу на процес передачі графічних даних у глобальних та локальних мережах. Сформовано підгрунття реалізації алгоритму Джексона та доведено, що дискретний марківський процес, що описує роботу мережі Джексона зі змінною структурою, ергодичний. Здійснено порівняльний аналіз описаних підходів з детальним порівнянням алгоритмів та визначення найбільш дієвого. Відокремлено фактори, які впливають на оптимізацію передачі пакетів графічних даних у локальних та глобальних мережах. Наголошено, що оптимізація мереж передачі даних призводить до кешування та стиснення переданих даних, оптимізації трафіку, зміни транспортного протоколу TSP, які збільшують інтерактивність продуктивності мережевого додатку та зменшують обсяг переданих даних.
\end{abstract}

Ключові слова: передача, збереження, масив, графічна інформація, локальна мережа, глобальна мережа, пакет, трафік.

Анищенко А. С. По вопросу передачи и сохранения массивов графических данных в глобальных и локальных сетях. В статье раскрыты вопросы передачи и сохранения массивов графических данных в глобальных и локальных сетях. Описана структура современных компьютерных сетей, определены основные проблемы, которые возникают при передаче данных внутри сети. Обозначена сложность моделирования глобальных и локальных сетей. Отмечается, что построение логической системы управления передачей графических данных в сетях позволит повысить скорость передачи и снизить возможности потери информации. Описано влияние модели Гилберта на линию передачи данных и обособленно механизм влияния скрытого харьковского процесса на передачу данных. Детализировано метод идентификации характеристик линии передачи и выбора оптимального метода кодирования сигнала, согласованного с текущей частотной характеристикой линии передачи. Раскрыта стохастическая теория управления в системах со скрытыми марковскими процессами и обосновано ее влияние на задачи управления системами передачи данных. Подчеркнуто, что основной проблемой в организации локальных и глобальных сетей является распределение потоков данных по кратчайшим путям. К такой проблеме относятся способы передачи данных, которые требуют минимального времени, или пути с минимальными помехами. Таким образом, на основе этого определения, отмечено, что оптимизация пути должна осуществляться по любым техническим и экономическим критериям, а выбранные пути должны гарантировать эффективное использование линий и вершин связи. Подробно описан алгоритм Дейкстры и определены направления его реализации и влияния на процесс передачи графических данных в глобальных и локальных сетях. Сформирована основа реализации алгоритма Джексона и доказано, что дискретный Марковский процесс, описывающий работу сети Джексона с переменной структурой, эргодичен. Осуществлен сравнительный анализ описанных подходов с детальным сравнением алгоритмов и определения наиболее действенного. Выделены факторы, которые влияют на оптимизацию передачи пакетов графических данных в локальных и глобальных сетях. Отмечено, что оптимизация сетей передачи данных приводит к кэширования и сжатия передаваемых данных, оптимизации трафика, изменения транспортного протокола TSP, которые увеличивают интерактивность производительности сетевого приложения и уменьшают объем передаваемых данных. трафик.

Ключевые слова: передача, сохранение, массив, графическая информация, локальная сеть, глобальная сеть, пакет,

Anyshchenko Oleksii. On the issue of transmission and storage of graphic data arrays in global and local networks. The article deals with the transfer and storage of graphic data arrays in global and local networks. The structure of modern computer networks is described, the main problems that arise when transmitting data within the network are identified. The complexity of modeling global and local networks is outlined. It is noted that the construction of a logical control system for the transmission of graphic data in networks will increase the transfer rate and reduce the possibility of information loss. The influence of the Gilbert model on the data transmission line is described and the mechanism of the influence of the hidden Kharkiv process on the data transmission is separated. The method of identifying the characteristics of the transmission line and selecting the optimal method of signal coding, consistent with the current frequency response of the transmission line, is detailed. The stochastic theory of control in systems with hidden Markov processes is revealed and its influence on the problems of data transmission systems control is substantiated. It is emphasized that the 
main problem in the organization of local and global networks is the distribution of data flows by the shortest paths. This problem includes data transmission methods that require minimal time, or paths with minimal interference. Thus, based on this definition, it is emphasized that the optimization of the path should be carried out according to any technical and economic criteria, and the chosen paths should ensure the efficient use of lines and vertices. Dijkstra's algorithm is described in detail and the directions of its implementation and influence on the process of graphic data transmission in global and local networks are determined. The basis for the implementation of Jackson's algorithm is formed and it is proved that the discrete Markov process describing the operation of Jackson's network with variable structure is ergodic. A comparative analysis of the described approaches with a detailed comparison of algorithms and determining the most effective. The factors influencing the optimization of the transmission of graphic data packets in local and global networks are singled out. It is emphasized that the optimization of data networks leads to caching and compression of transmitted data, traffic optimization, changes in the TSP transport protocol, which increase the interactivity of network application performance and reduce the amount of transmitted data.

Key words: transmission, storage, array, graphic information, local network, global network, packet, traffic.

Постановка проблеми. Для створення оптимальної системи управління інформаційними комп'ютерними мережами необхідно моделювати передачу, обробку та збереження даних. Комп'ютерні мережі можуть об'єднувати велику кількість підмереж з різною структурою, що наразі є великою проблемою.

Існує кілька ключових факторів, які визначають складність моделювання:

1) Масштаб. Мережа об'єднує кілька комп'ютерів і серверів, які зберігають і передають дані по лініях зв'язку;

2) Високий ступінь невідповідності елементів включає різноманітні типи комп’ютерів, обладнання зв'язку, операційні системи та програми;

3) Інформаційні комп'ютерні мережі об'єднують підмережі, використовуючи призначені лінії, супутникові, радіо, телефонні канали тощо.

Управління інформаційними комп'ютерними мережами має змінити передачу та обробку інформації в мережі. Глобальна та локальна мережі також повинні забезпечувати оптимальне використання ресурсів, а також сумісність мережевого обладнання та прогнозування роботи.

Було виявлено ряд проблем, які потребують вирішення в роботі комп’ютерних мереж глобального та локального рівнів. Ці завдання включають:

-забезпечення адаптивності алгоритмів управління в ситуаціях, коли наявної інформації недостатньо для прийняття рішень;

-прогнозування роботи комп'ютерної мережі для підвищення продуктивності управління;

-прийняття рішень, що відповідають реальним життєвим ситуаціям;

-забезпечення операційної системи самоуправлінням для ії вдосконалення.

Системи передачі даних часто працюють в умовах значних коливань властивостей лінії передачі, через які передаються дані. Такі коливання залежать від зовнішніх умов, а також від змін взаємного положення приймача-передавача.

При моделюванні таких каналів часто використовується модель прихованого марковського процесу. Окремим випадком цього процесу є модель Гілберта, в якій стан лінії передачі просто описується у термінах «добре» - «погано», а переходи між ними описуються ланцюгом Маркова. Оптимізація роботи передачі даних зазвичай полягає у максимізації вмісту трансінформації.

Таким чином, узгодження швидкості передачі даних з поточним станом лінії передачі набуває вирішального значення. Один з відомих розроблених підходів складається з ідентифікації характеристик лінії передачі та вибору оптимального методу кодування сигналу, узгодженого 3 поточною частотною характеристикою лінії передачі.

Аналіз останніх досліджень і публікацій. Чимало науковців підійшли до вивчення алгоритмів, методів, механізмів та принципів передачі пакетів у рамках комп'ютерних мереж. Так, варто відзначити роботу Ю. К. Давидовського, О. А. Реви та О. В. Малєєва [1], які обгрунтували важливість модернізації мереж передачі даних на прикладі зростання їх використання; визначили необхідність створення саме автоматизованого засобу для моделювання, на відміну від залучення технічних спеціалістів; здійснили вибір рівнів абстракції мережі передачі даних для іiі моделювання; визначили математичний апарат для обчислення параметрів моделі; розробили метод моделювання мережі передачі даних.

Л. П. Крючкова та В. О. Пшоннік [2] розглянули способи маршрутизації в мережах передачі даних, виконали порівняльний аналіз найбільш поширених протоколів маршрутизації. Обгрунтували доцільність застосування протоколу маршрутизації CJDNS для організації самоорганізовної мережі передачі даних в охоронних системах швидкого розгортання.

Методи багатошляхової маршрутизації в програмно-конфігурованих телекомунікаційних мережах дослідили О. А. Симоненко, О. О. Троцько та Д. М. Кушніренко [3]. Маршрутизацію пакетів для 
автономних систем інтернету з врахуванням трьох критеріїв розкрили К. Обельовська, Р. Панчишин та О. Ліскевич [4].

У [5] розкрито систему потокових моделей відмовостійкої маршрутизації без резервування елементів телекомунікаційної мережі за шляхами, що не перетинаються або перетинаються лише за вузлами. Новизною рішень $є$ введення в структуру моделей нелінійних умов використання шляхів заданого типу при балансуванні навантаження.

Iз зарубіжних авторів варто відзначити такі роботи як: Yang, Sheng-Hsiung \& Wu, Jenq-Lang [6], Zhang, Yu \& Xie, Shousheng \& Ren, Litong \& Wang, Lei [7], Pérez-Romero, Jordi \& Agustí, Ramon \& Sallent, Oriol [8], Yu, Peng \& Wu, Renke \& Zhou, Haojie \& Yu, Haibo \& Chen, Yuting \& Zhong, Hao [9], Praptodiyono, Supriyanto \& Firmansyah, Teguh \& Hasbullah, Iznan \& Osman, Azlan [10], Kimura, Mitsutaka \& Imaizumi, Mitsuhiro \& Araki, Takahito [11], Mutalemwa, Lilian \& Shin, Seokjoo [12], Patil, Leena \& Borkar, Gautam [13] та інші.

Проте, враховуючи описані наукові набутки, за темою, питання передачі та збереження масивів графічних даних у глобальних і локальних мережах залишається відкритим та потребує детального опрацювання.

Постановка завдання. Розкрити питання передачі та збереження масивів графічних даних у глобальних і локальних мережах.

Викладення основного матеріалу дослідження. Метод ідентифікації характеристик лінії передачі та вибору оптимального методу кодування сигналу, узгодженого 3 поточною частотною характеристикою лінії передачі, дає результати, дуже близькі до оптимальних, його апаратна реалізація досить складна. У той же час методи управління швидкістю передачі даних, які дозволяють узгодити іiї 3 поточним станом лінії передачі, менш ефективно використовуються в операційних системах зв'язку.

Наприклад, можна вказати протокол ТCP/IP, де швидкість пакетних пакетів зростає відповідно до лінійного закону, поки не відбудеться втрата пакета. Після цього швидкість спалаху поступово зменшується у фіксованій пропорції, а потім знову зростає за лінійним законом. Необхідно підкреслити, що цей метод управління $\epsilon$ типовою реалізацією стохастичного управління процесом на неповних даних. Насправді швидкість розриву втрат пакетів $є$ спостережуваним процесом, пов'язаним як 3 не спостережуваним станом лінії передачі, так і зі швидкістю пакетів графічних даних.

Швидкість пакетів даних також контролюється потоком даних і водночас - непрямими вимірами. В останні роки були запропоновані механізми управління, в яких безпосереднє вимірювання параметрів пакетів визначає трафік і мережа, налаштована таким чином, щоб забезпечити максимальну зручність користувача.

Моделі, що описують протокол ТCP/IP з точки зору стохастичних процесів, що експлуатуються прихованими марковськими процесами, останні роки були широко вивчені і довели свою ефективність при порівнянні результатів моделювання з практикою [14].

У той же час проста передача вже існуючих технічних рішень по бездротових лініях зв'язку призведе до, очевидно, неоптимального рішення, оскільки рівень коливань у лініях бездротового зв'язку та, що найголовніше, їх тимчасові характеристики значно відрізняються від тих, що $є$ у фіксованому оптоволоконному зв'язку перевізників і дротових лініях зв'язку.

3 іншого боку, у стохастичній теорії управління в системах із прихованими марківськими процесами є результати, які дозволяють сподіватися на успіх під час їх застосування у задачах управління системами передачі даних. Запропонований підхід грунтується на таких передумовах:

-стан каналу описується ходою Маркова з остаточним набором станів та відомою інтенсивністю переходів;

-швидкість передачі даних - це робочий параметр, а інтенсивність втрат пакетів - відома монотонна функція, що залежить від швидкості передачі та стану каналу;

-мета роботи - це вибір такого закону зміни швидкості передачі даних, за якого максимум середнього значення успішно досягнуто переданих пакетів масивів графічних даних [16].

Основною проблемою в організації локальних та глобальних мереж є розподіл потоків даних за найкоротшими шляхами. До такої проблеми належать способи передачі даних, які вимагають мінімального часу, або шляхи 3 мінімальними перешкодами. Відповідно, оптимізація шляху має здійснюватися за будь-якими технічними та економічними критеріями, а обрані шляхи мають гарантувати ефективне використання ліній та вершин зв'язку. Таким чином, необхідно провести порівняльний аналіз алгоритмів маршрутизації, які сьогодні використовуються для розробки та управління інформаційними потоками передачі масивів графічних даних. 
Адаптивне використання маршрутизації дозволяє скоротити середній час пошуку пакету в мережі, дає можливість скоротити витрати на його доставку одержувачам по мережах та підвищити загальну надійність мережі через автоматичний вибір маршруту на основі даних топології мережі. Але всі ці особливості надзвичайно навантажують комп'ютерні центри вершин. Тому використання адаптивної маршрутизації можливе в обмеженому режимі.

3 цієї причини виникає проблема розробки програмного забезпечення оптимізації вибору шляху 3 метою зменшення навантаження на обчислювальні центри, а також отримання можливості використання багатопрохідної маршрутизації.

Для вибору найбільш підходящого маршруту для відправки масивів графічних даних на наступний вузол будемо використовувати графік директиви. Вершини графіка $є$ маршрутизаторами, а ребра, що з'єднують вершини, - це фізичні лінії зв'язку, кожному з яких відповідає якесь інтегральне значення. Таке значення представлено «вартістю» передачі пакета на ньому, залежно від витраченого часу під час передачі даних.

Сьогодні існують деякі алгебраїчні методи, які дозволяють описати процес отримання результатів у формі, зручній для подальших досліджень. Для цього необхідно проаналізувати відомі методи для оцінки прикладної важливості та обмежень щодо їх використання.

Теорія черг відіграє важливу роль у моделюванні операцій передачі та збереження даних у комп'ютерних мережах. Свого часу використання теорії дозволило вирішити багато додатків, наприклад, моделювання магістральних мереж, які обслуговують трафік між системами.

Слід зазначити, що ця теорія охоплює широкий спектр моделей, серед яких можна згадати:

-мережі Джексона;

-мережі Маркова з різними класами вимог та параметрів, які залежать від стану;

-мережі 3 випадковим вибором каналу в блоці та узагальненим процесором спільного використання;

-вимоги до мереж систем масового обслуговування різних класів 3 абсолютним пріоритетом вхідних претензій та пріоритетом;

-мережі з дисципліною обслуговування «узагальнений спільний доступ до процесорів» та різними класами вимог;

-мережі черги з різноманітними каналами.

Багато «черг» і «каналів обслуговування», які отримують запити на обслуговування, $є$ предметом теорії доменів систем масового обслуговування. Цей математичний алгоритм розповсюджується в процесі подання заявки на аналіз комп'ютерних мереж. Попередники у своїх роботах обгрунтовували та виводили загальні закони запиту про затримку часу, довжини черги тощо, які залежать від типу масового обслуговування.

На основі масового обслуговування формування нових технологій передачі даних, а також поява глобальних мереж, які, у свою чергу, пов'язані з ростом інформації та безпекою комп'ютера, призвели до необхідності створення та розвитку нових моделей комп'ютерних мереж.

Існуючі методи зазвичай використовують перші два моменти (середнє значення та дисперсію) розподілу часу у вхідному потоці та часу обслуговування. Але вони досить невизначені, і не завжди вдається отримати достовірні результати. Тому деякі автори пропонують використовувати нові підходи.

Метод теорії черг дозволяє визначити розміри найкоротших шляхів між усіма вершинами, а також довжину всіх можливих шляхів між кожною множиною $з$ двох вершин мережі. Це дозволяє знайти найменші відстані в цій мережі.

Коротше кажучи, ці методи пов'язані з визначенням найкращої програми адміністративних дій у разі, коли лінійна залежність, у якій невідомі знаходяться на першому ступені, виступає як об'єктивна функція та обмеження.

Визначення проблеми лінійного програмування має крайній характер. Він полягає у визначенні таких змінних значень, за яких цільова функція досягає свого максимуму або мінімуму залежно від характеру проблеми.

Особливе місце в математичному супроводі процедур вибору трафіку передачі інформаційних потоків займає алгоритм Дейкстри, який базується на принципі оптимальності.

Алгоритм Дейкстри дозволяє знайти найкоротший шлях між одним вузлом у графі до всіх інших. Алгоритм працює тільки для графіків без ребер від'ємної ваги, хоча зараз існують узагальнені методи усунення цього недоліку (метод Дейкстри 3 потенціалами). Суть алгоритму Дейкстри полягає в поетапному побудові дерева найкоротших маршрутів з початкової вершини. У той же час необхідно 
після додавання на кожному етапі лінії зв'язку та вузла, щоб новоутворений найкоротший шлях був мінімально можливим на всіх кінцевих вершинах, які ще не знаходяться в дереві. Існують розраховані масштабні вектори шляхів і виправлені початкові вектори найкоротших шляхів у процесі створення дерева найкоротших шляхів. Складність алгоритму Дейкстри залежить від способу пошуку вершини $v$, а також від способу зберігання набору невідомих вершин та способу оновлення тегів. У графі $G, n$ і $m$ - це кількість вершин, а ребра для пошуку вершини, використовуючи найкоротший шлях до вершини $v$, переглядаються через всю множину $n$.

Час роботи алгоритму мінімізації становить $O\left(n^{2}+m\right)$. Для розряджених графіків (для яких $m<$ $<n)$ при використанні спеціальних алгоритмів оптимізації швидкості роботи час роботи може становити $O(n \log n+m \log n)$ або навіть $O(n \log n+m)$. Метод Дейкстри широко застосовується в мережевому програмуванні та технологіях, наприклад, він використовується у протоколі OSPF для усунення близьких шляхів. Використання модифікованого алгоритму Дейкстри як ефективного інструменту для розподілу вхідних інформаційних потоків у основних мережах IP з протоколом OSFP дозволяє покращити надійність мережі, захищаючи від перевантаження даних. Таким чином, можна використовувати залишкову ємність каналу як критерій розподілу інформаційних потоків. Необхідно віднести відносну простоту практичної реалізації методу до достоїнств протоколу.

Алгоритм Джонсона дозволяе знайти найкоротші шляхи між усіма парами вершин у розрідженому, зваженому по ребрах, спрямованому графі. Цей метод діє, якщо графік містить ребра 3 позитивною або негативною вагою, але немає циклів з негативною вагою. Краї зберігаються у вигляді списків суміжних вершин. Якщо в алгоритмі Дейкстри незмінна черга 3 пріоритетами реалізована у вигляді кубу Фібоначчі, час роботи алгоритму Джонсона дорівнює $O\left(n^{2} \lg n+n m\right)$.

Теорія графів використовується паралельно з теорією нечітких множин та теорією ймовірностей. Ця сумісність не дозволяє наблизити великий клас завдань до лінійного програмування.

В даний час теорія графів є одним з базових математичних алгоритмів, які використовуються для вивчення поведінки інформаційної комп'ютерної мережі на рівні мережі. Одним із рішень проблеми оптимізованої маршрутизації та зменшення потоку трафіку в кожному вузлі мережі $є$ використання теорії графів та мереж Петрі.

Класична мережа Джексона вивчається за припущення, що тривалість застосування сервісу має експоненційний розподіл. Закон розподілу часу подання послуг відрізняється від продемонстрованого. Існує актуальна проблема розвитку аналітичного апарату для вивчення мереж масового обслуговування 3 довільними функціями розподілу часу обслуговування, що приваблює все більше дослідників.

Існує метод обчислення характеристик стохастичних систем обробки додатків на основі дифузійних моделей. Процес функціонування вузла обробки додатків розглядається як двовимірний процес дифузії, який складається з двох потоків: потоку надходження заявок $(i=1)$ та потоку виходу $(i=2)$.

$$
\frac{\partial p\left(x_{i}, t\right)}{\partial t}=\sum_{i=1}^{2}\left\{a_{i} \frac{\partial^{2} p\left(x_{i}, t\right)}{\partial x_{i}^{2}}-b_{i} \frac{\partial p\left(x_{i}, t\right)}{\partial x_{i}}\right\}
$$

де $p(x, t)$ - допуск щільності ймовірності $(i=1)$, обробка $(i=2)$ запитів: $a$ - коефіцієнт дифузії, $b$ - коефіцієнт дрейфу. Крім того,

$$
\begin{gathered}
a=\frac{1}{\tau^{\prime}} \\
b=\frac{D}{\tau^{-3}}
\end{gathered}
$$

де $\tau$ - середній час між надходженнями заявок (обробка заявки), $D$ - розрізнення часу між надходженнями заявок (та / або обробкою заявок). обробки.

Такий підхід дозволяє використовувати ряд нових алгоритмів системи додатків стохастичної

Але мережева структура в цьому випадку відокремлена, і модель працює протягом середнього часу надходження та обслуговування додатків, під час відхилень надходження, під час простоїв технічного обслуговування програм та вузла. Таким чином, ця модель незручна.

Якщо динаміка обробки додатків не була проаналізована, то необхідно обчислити стаціонарний розподіл робочих / непрацюючих хостів Джексона зі зміною кількості сайтів, як для відкритих, так і для закритих мереж, де вузли можуть вийти з ладу або відновитися. 
Доведено, що якщо дискретний марківський процес, що описує роботу мережі Джексона зі змінною структурою, ергодичний, його граничний розподіл $P(n)$ задовольняє такому рівнянню:

$$
P(n)=\frac{\prod_{i=1}^{m}\left(\frac{\bar{\lambda}_{l}}{\mu_{i}}\right)^{n}}{\prod_{i=1}^{m} \frac{\mu_{i}}{\mu_{i}-\lambda_{i}}}
$$

де $\lambda_{i}$ та $\mu$ - інтенсивність вхідного та вихідного потоку додатків і -типу відповідно; $n$ - кількість робочих одиниць, $m$ - гранична кількість додатків різних типів.

Таким чином на основі вищевикладеного варто відзначити:

1. Для мереж з операцією інформаційного трафіку бажано використовувати метод Джонсона, оскільки він забезпечує збільшення швидкості у випадку топології мережі, яка описується великим графіком.

2. Серед алгоритмів одного шляху визначення відстані можна відзначити алгоритм Дейкстри (протокол OSFP). Цей алгоритм активно використовується як частина протоколу OSFP для $r$ маршрутизації в автономних системах (протокол внутрішнього блокування).

3. Матричний алгоритм, як і інші алгоритми багатопроменевого використання, має перевагу одного шляху, що складається із заздалегідь розрахованих альтернативних відстаней, що в підсумку призводить до підвищення надійності мережі та можливості перерозподілу навантаження між каналами зв'язку.

4. Визначення найкоротшого шляху може бути здійснено методами лінійного програмування, що дозволяє оцінити тимчасовий ефект відставання мережі за мінімізації середнього часу передачі повідомлення.

Висновки і перспективи подальших досліджень. У роботі розкрито питання передачі та збереження масивів графічних даних у локальних та глобальних мережах. Оптимізація передачі даних в локальних та глобальних мережах пов'язана з труднощами, викликаними такими факторами:

-необхідність постійного вивчення нових технологій передачі даних, їх особливостей та особливостей обладнання, що підтримує ці технології;

-жорсткі вимоги щодо вартості та тривалості реалізації мережевих проектів, а також потреби швидкої зміни потреб користувачів у часі, що призводить до необхідності організації командної роботи над проектами;

-інтерактивність процесу створення мереж передачі даних, пов'язана з безперервною появою нових послуг, збільшенням кількості клієнтів мереж та попитом на розширення існуючих користувачів.

Оптимізована передача та обробка даних у локальних та глобальних мережах значно скоротить час iii роботи, а також витрати на розробку та підтримку програмних продуктів.

Найважливіше в оптимізації локальних та глобальних мереж - це ряд інформаційних інструментів, які забезпечують постійний рівень надійності.

Зниження витрат на вдосконалення серверного програмного забезпечення пояснюється інтеграцією інформаційних ресурсів у центр обробки даних (або кількома ЦОД). Крім того, значно скорочуються витрати на послуги та передачу даних.

Тому оптимізація мереж передачі даних призводить до кешування та стиснення переданих даних, оптимізації трафіку, зміни транспортного протоколу TSP, які збільшують інтерактивність продуктивності мережевого додатку та зменшують обсяг переданих даних.

Перспективи подальших досліджень грунтуються на вдосконаленні алгоритму передачі масивів даних за рахунок об'єднання кількох підходів, зниження часу передачі та максимізації якості передачі.

Список бібліографічного опису.

1.Давидовський, Ю. К., Рева, О. А., \& Малєєва, О. В. (2018). Метод моделювання параметрів мережі передачі даних для iii модернізації. Innovative Technologies and Scientific Solutions for Industries, (4 (6)), 15-22.

2.Крючкова, Л. П., \& Пшоннік, В. О. (2018). Організація саморганізованої мережі передачі даних в ОСШР. Сучасний захист інформаиії, (3), 33-37.

3.Симоненко, А.А., Троцько, А.А., Кушніренко, Д.М. (2019). Аналіз методів багатошляхової маршрутизації в програмно-конфігурованих телекомунікаційних мережах. Збірник наукових праць BITI, 2, 95-104.

4.Обельовська, К., Панчишин, Р., \& Ліскевич, О. (2017). Маршрутизація пакетів для автономних систем інтернету 3 врахуванням трьох критеріїв. Вісник Національного університету Львівська політехніка. Комп'ютерні науки та інформаційні технології, (864), 83-89.

5.Лемешко, О. В., Сременко, О. С., \& Невзорова, О. С. (2020). Потокові моделі та методи маршрутизацї в інфокомунікачійних мережах: відмовостійкість, безпека, масштабованість. Хर. Харків : ХНУРЕ. http://openarchive.nure.ua/handle/document/12332

(C) Анищенко О. С. 
References.

1.Yang, Sheng-Hsiung \& Wu, Jenq-Lang. (2013). Output feedback multiple-packet transmission networked control systems. 2013 10th IEEE International Conference on Networking, Sensing and Control, ICNSC 2013. 615-620. 10.1109/ICNSC.2013.6548809.

2.Zhang, Yu \& Xie, Shousheng \& Ren, Litong \& Wang, Lei. (2019). Robust Packet Dropout Compensator Design for Multiple Packet Transmission Networked Control Systems. 1382-1389. 10.1109/HPCC/SmartCity/DSS.2019.00192.

3.Pérez-Romero, Jordi \& Agustí, Ramon \& Sallent, Oriol. (2021). TYPE-II HYBRID ARQ SCHEME IN A DS-CDMA PACKET TRANSMISSION NETWORK.

4. Yu, Peng \& Wu, Renke \& Zhou, Haojie \& Yu, Haibo \& Chen, Yuting \& Zhong, Hao. (2016). Multicast routing tree for sequenced packet transmission in software-defined networks. 27-35. 10.1145/2993717.2993721.

5. Praptodiyono, Supriyanto \& Firmansyah, Teguh \& Hasbullah, Iznan \& Osman, Azlan. (2016). PERFORMANCE EVALUATION OF ROUTING PROTOCOL ON IPV6 PACKETS TRANSMISSION.

6. Kimura, Mitsutaka \& Imaizumi, Mitsuhiro \& Araki, Takahito. (2021). Reliability of Congestion Control Based on Packet Transmission Interval with Hybrid ARQ. International Journal of Reliability, Quality and Safety Engineering. 2140004. $10.1142 / \mathrm{S} 0218539321400040$.

7. Mutalemwa, Lilian \& Shin, Seokjoo. (2019). Regulating the Packet Transmission Cost of Source Location Privacy Routing Schemes in Event Monitoring Wireless Networks. IEEE Access. PP. 1-1. 10.1109/ACCESS.2019.2943710.

8. Patil, Leena \& Borkar, Gautam. (2018). An Adaptive RIPng Routing Protocol with Secure Packet Transmission in MANETs. Journal of Applied Security Research. 13. 1-27. 10.1080/19361610.2018.1499385.

9.Ложковський, А. Г., Ложковский, А. Г., Удут, Т. І., Удут, Т. И., Удут, Я. І., \& Удут, Я. И. (2017). Дослідження впливу параметрів трафіку на якість обслуговування в системах з втратами та чергами. Інфокомунікації - сучасність та майбутнє: матеріали 7-ої Міжнар. наук-практ. конф., 26-27 жовтня 2017 р., Одеса. Одеса: ОНАЗ ім. О.С. Попова, 1, 81-84.

10.Трубчанінова, К., Ковтун, І. В., Рубльов, В. О., \& Соболєвська, Н. В. (2017). Дослідження значення величини середньої затримки пакета даних інформаційних потоків у мережах передачі даних. Інформаційно-керуючі системи на залізничному транспорті, (5), 16-25. 